\title{
DIVULGAÇÃO DE INFORMAÇÃO POR SEGMENTO DAS COMPANHIAS DE ÓLEO \& GÁS LISTADAS NA SEC
}

\section{DISCLOSURE OF SEGMENT REPORTING OF OIL \& GAS COMPANIES LISTED IN THE SEC}

0 artigo foi aprovado e apresentado no X Congresso de Administração, Sociedade e Inovação (CASI), realizado de 30/11 a 01/12 de 2017 em Petrópolis (RJ).

\begin{abstract}
RESUMO
A divulgação das informações por segmento permite às empresas evidenciarem os resultados diversificados de seus negócios. As empresas petrolíferas se encaixam nesta realidade, pois, além de terem grande importância na geração de riqueza, ainda atuam globalmente em diversos ramos de atividades. Nesse contexto, este estudo teve como objetivo identificar o nível de evidenciação das informações por segmento das empresas, verticalmente integradas, do ramo de óleo e gás nos anos de 2014 e 2015, de acordo com as normas norte-americanas e internacionais de contabilidade. O processo metodológico utilizado foi de análise documental dos critérios de segmentação das empresas da amostra, seguido de apuração de conteúdo de suas demonstrações contábeis. Os resultados evidenciaram índice de divulgação médio de $76 \%$. Apenas uma companhia atingiu $100 \%$ do que é exigido pelas normas. O menor índice de divulgação foi de 52,94\%, alcançado por duas empresas. Concluiu-se que, apesar da obrigatoriedade, as empresas analisadas, na sua quase totalidade, não atenderam aos itens de divulgação requeridos pelas normas, o que leva a questionar quais incentivos norteiam a divulgação das empresas e, além disso, até mesmo se os itens requeridos são, de fato, relevantes.
\end{abstract}

Palavras chave: Informação por Segmento. Nível de Evidenciação. IFRS 8. SFAS 131. CPC 22.

\begin{abstract}
The disclosure of segment reporting allows companies to highlight the diversified results of their business. Oil companies fit this reality, because, besides being of great importance in the generation of wealth, they still act globally in several branches of activities. In this context, this study aims to identify the level of disclosure of segment reporting of vertically integrated oil and gas companies in the years 2014 and 2015, in accordance with American and international accounting standards. The methodological process used was documentary analysis of the segmentation criteria of the sample companies, followed by content analysis of their accounting statements. The results show an average disclosure index of $76 \%$. Only one company has achieved 100\% of what is required by the standards. The lowest disclosure rate was $52.94 \%$, achieved by two companies. It is concluded that, in spite of the mandatory, the analyzed companies, in their almost totality, did not attend to the disclosure items required by the standards, which leads to question the incentives that guide the disclosure of the companies and, in addition, even if the required items are, in fact, relevant.
\end{abstract}

Keywords: Segment Reporting Disclosure. IFRS 8. SFAS 131. CPC 22.

\section{Priscila Pontes Nunes}

Mestre em Ciências Contábeis pela Faculdade de Administração e Ciências Contábeis (FACC) da Universidade Federal do Rio de Janeiro (UFRJ). Graduada em Ciências Contábeis pela Universidade Federal Fluminense (UFF). Contato: Av. Pasteur, 250, Sala 250, Campus Praia Vermelha, Urca, Rio de Janeiro, RJ, CEP: 22.290240. E-mail: priscilapontesnunes@gmail.com.

\section{Rafael de Argolo Kronemberg}

Mestrando em Ciências Contábeis pela Faculdade de Administração e Ciências Contábeis (FACC) da Universidade Federal do Rio de Janeiro (UFRJ). Graduado em Ciências Contábeis pela Universidade Federal Fluminense (UFF). Contato: Av. Pasteur, 250, Sala 250, Campus Praia VermeIha, Urca, Rio de Janeiro, RJ, CEP: 22.290-240. E-mail: rafaelkronemberg@gmail.com.

\section{Odilanei Morais dos Santos}

Doutor em Contabilidade pela Faculdade de Economia, Administração e Ciências Contábeis (FEA) da Universidade de São Paulo (USP). Graduado em Ciências Contábeis pela Universidade Federal do Pará (UFPA). Docente do curso de Ciências Contábeis na Universidade Federal do Rio de Janeiro (UFRJ). Contato: Av. Pasteur, 250, Sala 250, Campus Praia Vermelha, Urca, Rio de Janeiro, RJ, CEP: 22.290-240. E-mail: odilaneisantos@terra.com.br.

José Augusto Veiga da Costa Marques Pós-Doutorado em Contabilidade pela Faculdade de Economia, Administração e Ciências Contábeis (FEA) da Universidade de São Paulo (USP). Doutor em Administração pela Fundação Getúlio Vargas (FGV/SP). Docente do curso de Ciências Contábeis na Universidade Federal do Rio de Janeiro (UFRJ). Contato: Av. Pasteur, 250, Sala 250, Campus Praia Vermelha, Urca, Rio de Janeiro, RJ, CEP:22.290-240. E-mail: joselaura@uol.com.br. 


\section{INTRODUÇÃO}

Com o rápido aumento da globalização, avanço e diversificação do mercado de capitais, as empresas, de forma obrigatória ou voluntária, aumentaram o nível de transparência de suas demonstrações contábeis a fim de suprir as necessidades informacionais do mercado atual (AILLÓN et al., 2013).

Nesse contexto, foram criadas normas visando à melhoria da transparência das demonstrações contábeis e uma delas diz respeito às informações por segmentos. Trata-se de um mecanismo de divulgação de forma segregada dos efeitos financeiros de cada atividade de negócio em que as empresas estão envolvidas (COMITÊ DE PRONUNCIAMENTOS CONTÁBEIS, 2009).

As informações por segmento têm papel essencial na busca pela transparência. Esse tipo de informação reflete a segmentação das atividades das empresas, ou seja, como são estruturados internamente seus negócios (SOUZA; SARLO NETO, 2014).

Fernandes (2009) explica que os usuários das demonstrações contábeis encontraram dificuldades em realizar análises e projeções quando cenários diferentes são tratados de forma conjunta. Conforme Boscov (2009), tinha-se a necessidade de comunicação das informações para os diferentes públicos em uma linguagem universal. Dessa forma, as normas internacionais de contabilidade buscaram aperfeiçoar e minimizar essas dificuldades, por meio da divulgação das informações detalhadas por segmento, exigindo das empresas sua apresentação. Tal cenário também é percebido nas companhias que seguem as normas contábeis norte-americanas.

De acordo com Mourad (2009), os primeiros passos para essa normatização começaram a ser dados a partir da década de 1960. Entretanto, a primeira norma foi emitida em 1976 pelo Financial Accounting Standards Board (FASB), correspondendo ao Statement of Financial Accounting Standards $\mathrm{n}^{\circ} .14$ - Financial reporting for segments of a business enterprise (SFAS 14) e tinha apenas caráter de orientação às empresas para que publicassem, de forma voluntária, informações complementares em suas demonstrações contábeis. Posteriormente, o FASB substitui o SFAS 14, publicando em 1997 o Statement of Financial Accounting Standards $\mathrm{n}^{\circ} .131$ - disclosures about segments of an enterprise and related (SFAS 131) e tornando a divulgação por segmento obrigatória.

No mesmo ano de lançamento do SFAS 14, o International Accounting Standards Committee (IASC), atualmente Internacional Accounting Standards Board (IASB), emitiu o International Accounting Standard $\mathrm{n}^{\circ}$. 14 - segment reporting (IAS 14), sendo a norma internacional sobre o tema, mas que tinha caráter voluntário. Em 2007, o já IASB emitiu o International Financial Reporting Standards $\mathrm{n}^{\circ} .8$ - operational segment (IFRS 8), revogando o IAS 14 e tornando a divulgação das informações por segmento obrigatória.

No Brasil, a obrigatoriedade para a divulgação das informações por segmento se dá por meio do Comitê de Pronunciamentos Contábeis, que emitiu o Pronunciamento CPC nº 22 - informações por segmento (CPC 22) em 2009, recepcionando o IFRS 8 no processo de convergência do Brasil aos padrões internacionais de contabilidade. Com isso, a partir de 2010, as empresas brasileiras passaram a ser obrigadas a publicar as informações por segmento.

Um exemplo da importância das informações por segmento reside no entendimento do impacto da política de contenção de preços de combustíveis pelo governo brasileiro sobre o resultado da empresa Petrobras. Quando se olham simplesmente os lucros bilionários no período de 2010 a 2013, não é possível compreender o quanto a política de contenção de preços imposta à empresa lhe foi maléfica. A partir das informações por segmento, por outro lado, fica cristalino o quanto o resultado do segmento se deteriorou ao longo desses quatro anos, tendo, inclusive, no ano de 2012, gerado prejuízo muito maior que o lucro da empresa, como pode ser observado no Quadro 1.

Quadro 1: Resultado Líquido por Segmento da Petrobras

\begin{tabular}{|ccccc|}
\hline Segmento & $\mathbf{2 0 1 0}$ & $\mathbf{2 0 1 1}$ & $\mathbf{2 0 1 2}$ & $\mathbf{2 0 1 3}$ \\
E\&P & 29.558 & 40.575 & 45.452 & 42.266 \\
Abastecimento & 3.796 & $-9,970$ & -22.931 & -17.764 \\
Gás e Energia & 1.247 & 3.138 & 1.733 & 1.387 \\
Biocombustível & -92 & -157 & -218 & -254 \\
Distribuição & 1.276 & 1.175 & 1.793 & 1.843 \\
Internacional & 1.398 & 1.967 & 1.436 & 3.775 \\
Outros/Eliminação & -1.302 & -1.3578 & -6.306 & -8.246 \\
Total & 35.881 & 33.110 & 20.959 & 23.007 \\
\hline
\end{tabular}

Fonte: Adaptado de Almeida, Oliveira e Losekann (2015).

Nota: Os valores estão expressos em R\$ milhões.

Almeida, Oliveira e Losekann (2015) apontam que praticar preços no mercado brasileiro sem paridade com a cotação internacional proporcionou à Petrobras perdas de R $\$ 98$ bilhões. 
Motivados pelo debate envolvendo a Petrobras, ainda presente nos dias atuais, e pela importância das informações geradas nos resultados segmentados para os usuários, escolheram-se as empresas do setor de óleo e gás como objeto de estudo, especialmente as verticalmente integradas pelo fato de atuarem em toda a cadeia produtiva do setor, conforme esclarecem Silva, Marques e Santos (2009).

Dessa forma, tem-se um cenário em que a aplicação das normas sobre informações por segmento torna-se relevante, dada a necessidade de divulgação de informações segmentadas em função de suas variedades de negócios, o que torna interessante analisá-las quanto ao atendimento das normas contábeis correspondentes.

Assim, este estudo tem como objetivo verificar o nível de divulgação das empresas petrolíferas integradas no que tange aos requerimentos das normas contábeis (SFAS 131 e IFRS 8) de informações por segmento. Com isso, a pesquisa possui a seguinte questão: Qual o nível de divulgação das informações por segmento das empresas petrolíferas integradas listadas na Bolsa de Valores de Nova Iorque?

Para atender aos objetivos, utilizou-se amostra constituída por 16 empresas petrolíferas, verticalmente integradas, de atuação mundial com ações na Bolsa de Valores de Nova Iorque. A escolha de mercado americano decorre do fato de que, no Brasil, são poucas as empresas de capital aberto do setor de óleo e gás, sendo a Petrobras a única verticalmente integrada.

Aplicou-se a metodologia da análise de conteúdo nas demonstrações contábeis consolidadas (Formulário 10-K, Formulário 20-F e Formulário 40-F) dos anos de 2014 e 2015 para apurar o nível de divulgação das informações devido às exigências normativas contidas no SFAS 131 e IFRS 8. A escolha desse período decorre do fato de que as cotações internacionais do preço do petróleo e derivados tiveram forte oscilação para baixo, pressionando os resultados da companhia, sendo, portanto, a oportunidade para verificar o nível de divulgação das empresas (SENA, 2016).

Este trabalho justifica-se pela relevância em verificar se as empresas petrolíferas estão atendendo aos requerimentos das normas contábeis sobre informações por segmento, para, assim, permitir que as informações geradas sobre as atividades das empresas de forma individual sejam úteis e fidedignas. Como evidenciado, tem-se uma indústria cujas atividades possuem impacto direto na economia. Atendendo aos requisitos normativos, parte-se do pressuposto de que as informações divulgadas poderiam ajudar os usuários a entender a dinâmica dos resultados da empresa, em especial as petrolíferas, quando observados os seus diversos segmentos.

Além disso, a utilização de uma amostra com empresas petrolíferas se justifica pela grande influência destas companhias na economia mundial, as quais influenciam fortemente a geração de recursos, riquezas e investimentos, dado o petróleo ser, ainda, a principal fonte de energia utilizada no mundo, movimentando milhões de dólares diariamente. Conforme Ross (2015), a indústria do petróleo é a maior do mundo, respondendo por 14,2\% do comércio de commodities.

Tem-se, ainda, o contexto em que o IASB encontra-se em processo de revisão do IFRS 8 decorrente das possibilidades de melhorias identificadas durante a análise da pós-implementação da norma. Assim, os resultados deste estudo podem oferecer evidências àqueles que buscam participar do processo normativo internacional no sentido de constatar se a norma vem cumprindo o que se propunha.

Por fim, com exceção de Fernandes (2009), pesquisas anteriores já estudaram o nível de divulgação por parte das empresas do setor de óleo e gás, a exemplo de Malone, Fries e Jones (1993) e Silva, Marques e Santos (2009), mas tais estudos não abordaram o atendimento às normas de informações por segmento como aqui proposto, o que torna este trabalho relevante academicamente.

Este estudo está dividido em cinco seções. A primeira seção é a introdução, que trata da contextualização do tema e abordagem do objetivo e justificativa da pesquisa. A segunda apresenta o referencial teórico, que aborda os principais conceitos e aspectos relacionados à divulgação de informações sobre segmentos. Na terceira seção encontra-se a descrição da metodologia utilizada para a realização do artigo; enquanto os resultados e discussões, bem como as considerações finais, são apresentados nas duas últimas seções.

\section{REFERENCIAL TEÓRICO}

A seguir, apresentam-se as teorias que suportam o entendimento da problemática desenvolvida, notadamente a teoria da divulgação e considerações sobre escolhas contábeis. Por fim, apresentam-se resultados de estudos anteriores sob dois aspectos: estudos que trataram do atendimento aos requerimentos das normas contábeis sobre informações por segmento de maneira geral, sem focar empresas petrolíferas e, ainda, estudos que tiveram como amostra empresas petrolíferas e que trataram sobre aspectos de divulgação.

\subsection{Teoria da Divulgação}

A regulação pode ser entendida como um conjunto de normas coercitivas relativas à determinada atividade ou área de conhecimento e que são emanadas pelo Estado ou por órgãos ou entidades privadas com autoridade para tanto (POHLMANN; ALVES; 2004). Na área da contabilidade, segundo Lev (1988), a regulação diz respeito ao conjunto de leis, normas e princípios contábeis geralmente aceitos e que tratam da oportunidade, conteúdo, forma e periodicidade do reporte das demonstrações contábeis.

A regulação contábil ganhou corpo a partir da quebra da Bolsa de Valores de Nova Iorque, em 1929, quando cresce- 
ram as demandas sobre os órgãos reguladores, auditores e contadores para melhor qualidade das informações contábeis divulgadas pelas empresas, pois, até então, como expõem Kothari, Ramanna e Skinner (2010), as práticas contábeis eram largamente determinadas pelas próprias empresas e firmas de auditorias, mas sem que houvesse uma coordenação formal para formatação das práticas, daí advindo a expressão de 'princípios contábeis geralmente aceitos'.

Esse movimento de emissão de normas contábeis, segundo Pohlmann e Alves (2004), reflete o desejo de segurança e objetividade da informação produzida pela contabilidade, mas isso só faz sentido porque as empresas de maneira espontânea não evidenciariam o volume adequado de informações contábeis.

Levitt (1998) esclarece que essa condição de obrigatoriedade foi a corrente seguida desde que a Securities And Exchange Commission (SEC) foi criada para permitir que determinada empresa tenha seus títulos negociados no mercado norte-americano, ou seja, obrigar que atenda às exigências de divulgação das informações contábeis visando evitar divulgações incompletas e tendenciosas. King (2006) complementa argumentando que oportunidade e exatidão na divulgação das informações contábeis foram consideradas a condição necessária para o correto funcionamento do mercado de capitais norte-americano.

Ainda nessa linha de qual seria a função da regulação, Stigler (1971) expõe que sua função seria proteger e beneficiar o mercado ou pelo menos a maior parte dele. Isto faz sentido quando se considera que boa parte da dinâmica das organizações gira em torno de contratos, formais ou informais, e que a maximização de sua riqueza passa pela redução dos custos contratuais, grande parte via redução da assimetria informacional.

Murcia e Santos (2009a) observam que, ao se reduzir a assimetria informacional com a regulação, busca-se proteger os investidores menores (menos informados), e o remédio mais efetivo seria remover a vantagem que os investidores mais bem informados possuem, exigindo das empresas a divulgação de informações que aumentem o bem-estar do mercado como um todo, argumentos estes também apresentados por Beaver (1998) e Lev (1988).

Fields, Lys e Vicent (2001) afirmam que a regulação da contabilidade afeta a quantidade e a qualidade das informações divulgadas. Em outros termos, a qualidade dos números e das demonstrações contábeis geradas pelo processo contábil irá variar de acordo com os incentivos recebidos pelos agentes, pela demanda do mercado por demonstrações mais informativas ou pela sua regulação (ALMEIDA, 2010).

A regulação da contabilidade apresenta diversos motivos, sendo que boa parte deles se refere à redução da assimetria informacional, proteção dos pequenos investidores (menos informados) e padronização das informações (transparência e comparabilidade) (LEV, 1988; BEAVER, 1998; CHUNG, 1999; MURCIA; SANTOS, 2009a e 2010b).

Murcia e Santos (2009b) argumentam que a função da regulação é gerar comprometimento por parte da empresa, uma vez que lhe obriga a divulgar informações em tempos bons ou ruins, ou seja, "é uma forma de forçar a divulgação de informações mesmo quando isso trouxesse mais malefícios do que benefícios” (MURCIA; SANTOS, 2009b, p. 7). A conclusão é a de que as empresas não estariam dispostas a aumentar o nível de divulgação de suas informações, a não ser quando obrigadas.

De acordo com Chung (1999), acredita-se que os padrões contábeis emitidos possuem a intenção de aumentar a qualidade das informações contábeis e reduzir a assimetria informacional entre os participantes do mercado. Nesse sentido, entre os objetivos seguidos pelos normatizadores como IASB, destacam-se os de desenvolver padrões contábeis de alta qualidade e de aplicabilidade mundial que permitam a transparência e comparabilidade das informações divulgadas nas demonstrações financeiras, com vista a ajudar os participantes do mercado a tomarem decisões econômicas (LEVITT, 1998; BARTH; LANDSMAN; LANG, 2008).

De acordo com Levitt (1998) o sucesso do mercado de capitais depende diretamente da qualidade das informações contábeis e do sistema de disclosure, os quais só são possíveis com normas contábeis de alta qualidade, permitindo aos investidores confiar nas demonstrações contábeis.

Em que pese toda essa discussão, ainda não existe consenso sobre o porquê de as práticas contábeis precisarem ser reguladas, bem como se de fato tal regulação é necessária para facilitar a alocação eficiente de recursos (KOTHARI; RAMANNA; SKINNER, 2010).

Como esclarece Lev (1988), em função da vasta gama de usuários das demonstrações contábeis e como não se sabe com precisão que informações são efetivamente relevantes para esses usuários, não está claro qual critério os órgãos reguladores deveriam utilizar para decidir o que deveria ou não ser divulgado pelas empresas.

Neste contexto, têm-se as normas referentes à divulgação obrigatória das informações por segmento, seja o SFAS 131, no caso das normas norte-americanas ou o IFRS 8, no caso das normas internacionais. Assim, considerando-as normas de alta qualidade, por um lado espera-se que as empresas atendam integralmente seus requisitos, mas por outro sabe-se que, conforme Ball, Kothari e Robin (2000), a qualidade da informação contábil não depende apenas de normas e leis, mas grandemente dos incentivos que os gestores possuem para divulgar ou deixar de divulgar uma informação.

\subsection{Escolhas Contábeis}

De acordo com Fields, Lys e Vincent (2001), as escolhas contábeis geralmente são relacionadas a alguns fatores referentes às imperfeições de mercado como: a assimetria informacional, que se encontra geralmente associada à relação entre gestores e investidores; a externalidades, comumente associadas às relações contratuais ou não com terceiros; e custos de agência, referentes a aspectos contratuais como remuneração de administradores. Estas proxies delimitadas 
pelos autores existem devido aos contratos incompletos entre os principais e os agentes, assim como também pela ausência de um mercado perfeito (PERLINGEIRO, 2009).

Watts (1992) afirma que se referem à escolha do gestor de um método contábil em relação a outro, como é o caso da escolha do tipo de depreciação. Além disso, as escolhas contábeis incluem as escolhas realizadas por órgãos regulares como o FASB e IASB no que tange às normas contábeis por estes emitidas.

Segundo Browen, Durcharme e Shores (1999), os estudos empíricos que investigaram a relação entre a tomada de decisão do investidor e as escolhas contábeis dos gestores geralmente se devem aos incentivos de curto prazo. Dessa forma, cada stakeholder possui uma diversidade de usos da informação contábil que podem influenciar a forma com que as escolhas contábeis são feitas.

Christie e Zimmerman (1994) evidenciam dois motivos para explicar as decisões nas escolhas contábeis, que são o oportunismo, referente ao fato de os gestores poderem escolher diferentes métodos contábeis a fim de aumentar seu bem-estar à custa de outros stakeholders; e o segundo motivo consiste em aumentar o valor da firma.

O primeiro motivo se fundamenta na intenção dos gestores em utilizar procedimentos contábeis que melhorem o lucro a fim de aumentar a remuneração por meio de planos com base em ganhos reportados; e para reduzir a probabilidade de que o gestor seja dispensado por seu baixo desempenho operacional (CHRISTIE; ZIMMERMAN, 1994).

O segundo motivo, que indica a maximização do valor da firma, é fundamentado em algumas hipóteses como: empresas que assumem o controle de outras; decisões a serem tomadas sobre mecanismos de escolha do método contábil; aspectos referentes a impostos; entre outros registros (CHRISTIE; ZIMMERMAN, 1994).

De acordo com Fields, Lys e Vincent (2001), a escolha contábil existe porque se torna praticamente impossível ou inviável eliminar a flexibilidade no processo contábil. Torna-se difícil encontrar um padrão contábil que possa oferecer uma linguagem de divulgação que atenda às necessidades de todas as empresas em todos os segmentos e mercados.

As escolhas contábeis são essenciais no que tange às informações por segmento, pois estas informações podem diminuir a assimetria informacional, ao mesmo tempo que podem servir para relações contratuais com terceiros (clientes ou fornecedores, por exemplo). O levantamento dos índices de divulgação das companhias pode servir como evidência para a identificação das escolhas contábeis dos gestores das empresas analisadas, em relação ao que é divulgado nas notas explicativas sobre as informações por segmento.

\subsection{Pesquisas Anteriores}

Com base na busca pelo tema Informações por Segmento, pôde-se observar que as pesquisas predecessoras analisaram a forma, a relevância e o nível de evidenciação das informações por segmento. A seguir, passa-se a relacionar tais pesquisas.

No estudo de Emmanuel e Garrod (2002), foi investigado se a relevância e a comparabilidade são mutuamente exclusivas ou podem ser simultaneamente alcançadas na divulgação das informações segmentadas. A pesquisa conclui que um ou outro, ou ambos, são refletidos na maioria da amostra de empresas analisadas. Cerca de $20 \%$ da amostra não apresentou nem relevância e nem comparabilidade.

O estudo de Vasconselos e Szuster (2003) verificou 30 empresas listadas na B3 (antiga BM\&FBovespa) e com títulos emitidos no mercado internacional, tendo por base os dados publicados no exercício de 2001. A pesquisa teve a finalidade de avaliar a qualidade da evidenciação voluntária de informações contábeis por segmento no Brasil, tendo como parâmetro os requerimentos da IAS 14, ou seja, no contexto de divulgação voluntária.

Vasconselos e Szuster (2003) evidenciaram que 57\% das empresas da amostra apresentaram informações por segmento no relatório de administração e $17 \%$ em notas explicativas. De todas as companhias, apenas $26 \%$ não apresentaram nenhum tipo de informação relacionada a segmentos no mercado brasileiro. Os autores não conseguiram confirmar se as empresas que emitem títulos no exterior apresentam melhores informações no mercado nacional, ou seja, a falta de legislação exigindo a publicação fazia com que as empresas publicassem as informações no mercado externo, mas não no Brasil.

A pesquisa de Kou e Hussain (2007) teve por objetivo fornecer uma análise detalhada das características multidimensionais dos relatórios por segmento. A medição foi feita com base nas características das informações segmentadas por meio do índice FTSE-100 e concluíram que os segmentos de negócios estavam sendo relatados de forma padronizada e compatíveis com os setores da indústria e das regiões geográficas, apresentando um alto grau de comparabilidade.

Mourad (2009) demonstrou que a qualidade das informações passíveis de divulgação pelas companhias pode sofrer influência direta por causa do custo da concorrência. Por meio de questionário enviado aos profissionais com conhecimento em IFRS, apurou-se que as empresas possuem informações privilegiadas e estratégicas que não querem divulgar ao mercado. Nessa mesma linha, em entrevista realizada por Boscov (2009, p. 90) a um executivo, obtém-se a opinião de que "[...] um problema da norma é que as empresas divulgam só o que elas querem, selecionam as informações".

No contexto da adoção do CPC 22 no Brasil, Boscov (2009) averiguou, ainda, que a implementação desta norma não seria fácil, rápida e barata, pois existiam inconsistências geradoras de problemas que afetariam a parametrização de sistemas contábeis, a comunicação entre as áreas gerenciais e financeiras, apresentam resistências internas de implementação, necessidade de elevado detalhamento de dados, reflexo em aumento no preço da auditoria e da publicação das informações.

Fernandes (2009) objetivou identificar diferenças nas informações por segmentos divulgadas pelas empresas pe- 
troliferas. Como resultado, o autor identificou aspectos somente na visão segmentada, como o crescimento de diversos negócios, locais onde são realizados, informações sobre as origens das receitas da empresa, e os negócios que os geram. De modo geral, os itens divulgados atenderam as normas, pois $90 \%$ alcançaram a maior classificação em relação ao nível de aderência. As conclusões foram que tanto dados brutos (valores) quanto a aplicação em apuração de indicadores foram úteis quando a intenção é a comparação na indústria do petróleo.

Em estudo realizado na Malásia, Talha e Salim (2010) analisaram 374 empresas listadas na bolsa local, com o objetivo de verificar fatores que influenciam a escolha de empresas por segmento de negócios ou geográfico como segmento primário. Foram observados dados referentes ao exercício de 2006 e constatou-se que tamanho, desempenho financeiro e setor industrial têm significativo impacto na escolha do segmento primário em detrimento da informação geográfica.

A pesquisa de Schvirck, Lunkes e Gasparetto (2013) teve como objetivo identificar como foram definidos e quantos são os segmentos publicados, relacionando os resultados com as características corporativas de 81 empresas da bolsa. Os autores destacaram a importância da evidenciação das informações por segmento como meio de análise dos usuários das informações contábeis e concluíram que as grandes empresas, provavelmente por atuarem em mercados maiores, apresentam a tendência de definir os segmentos com mais de um critério.

Souza e Sarlo Neto (2014) abordaram a relevância das informações por segmento e concluíram que quanto maior a empresa, maior o seu nível de divulgação sobre segmentos, ou seja, na mesma direção de Schvirck, Lunkes e Gasparetto (2013). Outro fator observado neste estudo é o grau de endividamento da empresa, o qual exerce influência positiva sobre a divulgação, ou seja, quanto maior o grau de endividamento da empresa, maior é o nível de divulgação sobre segmentos.

Aillón et al. (2013) verificaram como são demonstradas nas notas explicativas de informações por segmento as informações gerenciais das empresas que compõem o IBrX-50. Os resultados apresentam baixo nível de divulgação em sua pesquisa, de apenas $48 \%$. Os autores também testaram se algumas variáveis explicariam o índice de divulgação das empresas. Foi identificado que somente a variável lucro líquido foi significante, o que mostra que as empresas que possuem lucros divulgam mais que as que possuem prejuízo. Também foi encontrado um baixo de nível de evidenciação de informações gerenciais, no que se refere às exigências das normas internacionais, o que pode ser justificado pela discricionariedade dos gestores na divulgação.

Schvirck (2014) avaliou, por meio de um indicador do nível de disclosure, se as informações por segmento das entidades que compõem o mercado de capitais brasileiro têm impacto sobre o seu desempenho. Primeiramente o autor afirmou que o CPC 22 é eficaz no tange à melhoria da transparência para os usuários das informações contábeis, porém identificou que houve um reporte de demonstrativos com informações por segmento em somente $43 \%$ das empresas estudadas.

Schvirck (2014) também identificou algumas características determinantes de empresas que divulgam informações por segmentos com mais frequência, sendo elas: tamanho da empresa, setor de atuação e nível de governança corporativo na BM\&FBovespa.

Ao pesquisar o nível de evidenciação das informações por segmento nas demonstrações contábeis e quais fatores podem influenciar o nível de divulgação das empresas pertencentes à B3, Weschenfelder e Mazzioni (2014) verificaram que, devido à definição dos parâmetros de como as informações a serem evidenciadas são definidas internamente, percebe-se um baixo índice de evidenciação. Exceto a variável emissão de ADRs, as demais não possuem relação significativa com o nível de evidenciação por segmentos.

O estudo de Viera e Borba (2015) apresenta que, após o processo de implementação do IFRS 8, foi iniciada a revisão da norma pelo IASB aproximadamente dois anos após a exigência de apresentação das demonstrações contábeis. Esta revisão foi consubstanciada por meio de cartas-comentários ao Post Implementation Review (PIR) recebidas pelo IASB. Pôde-se observar, por meio da análise das 12 cartas-comentários enviadas pelas empresas ao IASB que aquelas adotaram o IFRS 8 integralmente, respeitando as exigências do padrão, e que algumas divulgaram informações adicionais. A metade desses respondentes, especificamente seis empresas, aponta a não ocorrência de custos significativos e não previstos. Ao contrário, aqueles que relataram a existência de custos afirmaram ser esses decorrentes do modelo organizacional da empresa que precisou ser adaptado para divulgar informações segmentadas geograficamente. Sobre as medidas não IFRS, a mais citada foi o Earning Before Interest, Taxes, Depreciation and Amortization (EBITDA). As empresas, em sua maioria, consideram o texto normativo claro.

Importante destacar que empresas do setor de óleo e gás já foram objeto de estudos sobre divulgação. Malone, Fries e Jones (1993) investigaram os fatores determinantes do nível de disclosure financeiro de 125 companhias e nessa pesquisa o índice de disclosure não foi construído com base nos requerimentos normativos, mas por meio de um questionário com 129 itens construído pelos próprios pesquisadores. Os resultados indicaram índices de disclosure entre 20,2\% e $66,4 \%$.

Silva, Marques e Santos (2009), por sua vez, analisaram o nível de divulgação das informações das perdas por impairment das empresas petroliferas listadas na SEC, tendo por base as normas contábeis IAS 36 e SFAS 144 e as demonstrações contábeis de 2005. Os resultados indicaram que as companhias não atenderam a todos os requerimentos de divulgação.

Como se vê, na literatura há um conjunto de pesquisas que trataram da divulgação das informações por segmento, mas sem abordar o setor petrolífero propriamente dito, enquanto algumas outras até estudaram as empresas petrolíferas, 
mas em outros contextos que não as informações por segmento. Assim, frente aos estudos anteriores, evidencia-se que este trabalho supre uma lacuna na literatura existente por abranger um segmento econômico específico, como é o caso do setor petrolífero, possibilitando uma amostra de empresas de abrangência mundial e, além disso, conjuga os requerimentos das normas sobre informações por segmento no contexto do USGAAP e do IFRS.

\section{METODOLOGIA}

Este estudo é de natureza qualitativa, compreendendo a análise das notas explicativas das companhias selecionadas para, a partir delas, calcular os índices de aderência das divulgações. Caracteriza-se também como documental, pois consiste na coleta de "materiais que não receberam ainda um tratamento analítico, ou que ainda podem ser reelaborados de acordo com os objetivos da pesquisa” (GIL, 1999), que neste caso são as demonstrações contábeis das empresas.

Em relação aos dados, é realizada uma análise de conteúdo, que segundo Collis e Hussey (2005, p. 240), “é uma maneira de converter sistematicamente texto em variáveis numéricas para análise quantitativa de dados".

A população-alvo da pesquisa compreendeu as empresas petrolíferas integradas relacionadas no The Definitive Annual Ranking of the World's Largest Listed Energy Firms (INFORMATION HANDLING SERVICES, 2014), tradicional ranking do setor de energia, incluindo o segmento de óleo e gás. A definição da amostra compreendeu as empresas ranqueadas pela IHS (Information Handling Services) que tivessem ações listadas na bolsa de valores de Nova Iorque, visando o acesso padronizado às demonstrações contábeis anuais. Além disso, que tais empresas apresentassem divulgação de informações por segmento em USGAAP ou IFRS.

O ranking da IHS relacionava 25 empresas verticalmente integradas, e dessas, dezesseis possuíam registro na New York Stock Exchange (NYSE). Isso permitiu a verificação quanto à divulgação de informações por segmento dessas empresas. A escolha da NYSE decorre do fato de no Brasil existir apenas uma empresa classificada como petrolífera integrada e de haver empresas que tanto seguem o SFAS 131 quanto o IFRS 8. As empresas da amostra e seu respectivo valor de mercado, conforme o ranking da IHS, são apresentadas no Quadro 2.

Quadro 2: Amostra da Pesquisa

\begin{tabular}{|cccc|}
\hline Empresa & $\begin{array}{c}\text { Valor de Mercado } \\
\text { (Em US\$ bilhões) }\end{array}$ & Empresa & $\begin{array}{c}\text { Valor de Mercado } \\
\text { (Em US\$ bilhões) }\end{array}$ \\
\hline ExxonMobil & 442,1 & Eni & 87,6 \\
Chevron & 240,2 & CNOOC & 83,0 \\
Royal Dutch Shell & 233,8 & Ecopetrol & 78,8 \\
PetroChina & 229,4 & Statoil & 77,2 \\
BP & 150,7 & Suncor & 52,2 \\
TOTAL & 145,9 & Imperial Oil & 37,5 \\
Petrobras & 91,0 & TransCanada & 32,3 \\
Sinopec & 88,2 & Sasol & 31,8 \\
\hline
\end{tabular}

Fonte: IHS (2014, p. 2).

As empresas da amostra somam valor de mercado de aproximadamente US\$2,1 trilhões, com média de US\$131,4 bilhões. Com base nesse parâmetro, seis empresas apresentam-se com valor de mercado acima da média, podendo-se, para efeito das análises que são realizadas, ser consideradas como as grandes do setor.

Os dados necessários para a realização desta pesquisa foram coletados no site da Securities and Exchange Commission (SEC), em que foram obtidas as demonstrações contábeis anuais das empresas da amostra contidas nos Formulários 10-K, para empresas norte-americanas; Formulários 40-F, para as empresas canadenses; e nos Formulários 20-F, para as empresas de outros países que possuem ações no mercado norte-americano.

A análise se baseou na constatação das exigências mínimas requeridas pelas normas SFAS 131 (USGAAP) e IFRS 8 (normas internacionais) para divulgação sobre segmentos de negócios nos exercícios de 2014 e 2015. Utilizou-se o checklist elaborado por Fernandes (2009), o qual está adaptado tanto para as empresas que utilizam o padrão USGAAP quanto para as que utilizam o padrão IFRS, pois o checklist possui os requisitos mínimos em comum das duas normas. $\mathrm{O}$ Quadro 3 contém os itens verificados. 
Quadro 3 - Parâmetros de Aderência às Normas de Informações por Segmento

Itens mínimos de divulgação

1 Elementos utilizados para identificar os segmentos relatados da entidade

2 Tipos de produtos e serviços a partir dos quais cada segmento relatado deriva suas receitas.

3 Informações sobre ativos dos segmentos

4 Informações sobre lucros e prejuízos dos segmentos

5 Informações sobre passivos dos segmentos (para empresas que adotam a norma IFRS)

6 Reconciliações dos itens por segmentos e os montantes totais da entidade

Principais detalhamentos requeridos

$7 \quad$ Receitas de clientes externos

8 As receitas de transações com outros segmentos operacionais da mesma entidade

9 Receitas financeiras

10 Despesas financeiras

11 Depreciação, exaustão e amortização

12 Resultado com investimentos avaliados pelo método de equivalência patrimonial

13 Despesas ou benefícios com impostos sobre os rendimentos (imposto de renda)

14 Outro Itens Materiais de Resultado usados pelo tomador de decisão

15 Valor do investimento em empresas contabilizado pelo método de equivalência patrimonial

16 Total de adições a outros Ativos não Circulantes, com exceções normativas Mensuração

17 As bases de contabilização de transações intersegmentos.

18 Existência de divergência na mensuração por segmento e societário Outros

19 Informações dos segmentos por área geográfica, quando não usada na definição do segmento operacional.

Fonte: Fernandes (2009, p. 53).

A análise é feita tomando-se por base o grau apurado por meio do índice de aderência aos parâmetros das normas de divulgação da informação por segmento, que buscará refletir o nível de evidenciação dos itens propostos.

O checklist de Fernandes (2009) possui 19 itens. Se a empresa divulga a informação solicitada, é atribuído 'valor 1'. Se a empresa não divulga determinado item, é atribuído ‘valor 0’. No caso do quesito não se aplicar, o item será preenchido com a sigla N/A (não aplicável). O Índice de Divulgação (ID) é calculado dividindo-se o somatório de itens divulgados pelo total de itens aplicáveis, conforme fórmula a seguir.

IDINF.SEG $i=\frac{\sum \text { QTDE ITENS DIVULGADOS }}{19-\sum N / A_{i}}$

Em que:

IDINFSEGi: índice de divulgação das informações por segmento da empresa $i$.

Com base no índice de divulgação apurado, é apresentada a situação de cada empresa da amostra e como a divulgação se comporta considerando os parâmetros 'exigências mínimas', 'principais detalhamentos' e 'mensuração'. Além disso, são apresentados a quantidade de segmentos divulgados e o critério utilizado pela empresa para definição de seus segmentos, se por negócio ou área geográfica.

Entre as limitações metodológicas, ressalta-se que a amostra é não probabilística e por conveniência, considerando apenas as empresas petrolíferas integradas, sendo, portanto, os resultados restritos a elas, ou seja, não podem ser generalizados.

\section{APRESENTAÇÃO E ANÁLISE DOS RESULTADOS}

Destaca-se, primeiramente, que os resultados obtidos para os anos de 2014 e 2015 foram exatamente os mesmos. Dessa forma, os resultados contidos nos quadros a seguir valem para os anos de 2014 e 2015, igualmente.

O Quadro 4 evidencia o atendimento aos itens requeridos pelas normas, com detalhamento de cada empresa. Observa-se que todas as empresas divulgaram os itens: 1- Elementos utilizados para identificar os segmentos relatados da entidade; 2 - Tipos de produtos e serviços a partir dos quais cada segmento relatado deriva suas receitas; 4 - Informações sobre lucros e prejuízos dos segmentos; 8 - As receitas de transações com outros segmentos operacionais da mesma entidade; e 19 - Informações dos segmentos por área geográfica, quando não usada na definição do segmento operacional. 
Quadro 4: Índice de Divulgação dos anos de 2014 e 2015

\begin{tabular}{|c|c|c|c|c|c|c|c|c|}
\hline Itens & BP & Chevron & CNOOC & $\begin{array}{c}\text { Ecope- } \\
\text { trol }\end{array}$ & Eni & Exxon & $\begin{array}{c}\text { Imperial } \\
\text { Oil }\end{array}$ & Petrobras \\
\hline 1 & 1 & 1 & 1 & 1 & 1 & 1 & 1 & 1 \\
\hline 2 & 1 & 1 & 1 & 1 & 1 & 1 & 1 & 1 \\
\hline 3 & 1 & 1 & 1 & 0 & 1 & 1 & 1 & 1 \\
\hline 4 & 1 & 1 & 1 & 1 & 1 & 1 & 1 & 1 \\
\hline 5 & 0 & N/A & 1 & 0 & 1 & N/A & N/A & 0 \\
\hline 6 & 1 & 1 & 1 & 1 & 1 & 1 & 1 & 1 \\
\hline 7 & 1 & 1 & 1 & 0 & 1 & 1 & 0 & 1 \\
\hline 8 & 1 & 1 & 1 & 1 & 1 & 1 & 1 & 1 \\
\hline 9 & 1 & 1 & 1 & 1 & 1 & 1 & 1 & 1 \\
\hline 10 & 1 & 1 & 1 & 1 & 1 & 1 & 1 & 1 \\
\hline 11 & 1 & 1 & 1 & 1 & 1 & 1 & 1 & 0 \\
\hline 12 & 0 & 0 & 0 & 0 & 1 & 1 & 0 & 0 \\
\hline 13 & 1 & 1 & 1 & 1 & 1 & 1 & 1 & 0 \\
\hline 14 & N/A & $\mathrm{N} / \mathrm{A}$ & N/A & N/A & N/A & N/A & N/A & $\mathrm{N} / \mathrm{A}$ \\
\hline 15 & 0 & 0 & 0 & 0 & 1 & 1 & 0 & 0 \\
\hline 16 & 1 & 0 & 0 & 0 & 1 & 0 & 0 & 1 \\
\hline 17 & 1 & 1 & 1 & 1 & 1 & 1 & 1 & 1 \\
\hline 18 & N/A & N/A & N/A & N/A & N/A & N/A & N/A & N/A \\
\hline 19 & 1 & 1 & 1 & 1 & 1 & 1 & 1 & 1 \\
\hline Total & 14 & 13 & 14 & 11 & 17 & 15 & 12 & 12 \\
\hline ID & $82 \%$ & $81 \%$ & $82 \%$ & $65 \%$ & $100 \%$ & $94 \%$ & $75 \%$ & $71 \%$ \\
\hline Itens & Petrochina & Shell & Sasol & Sinopec & Statoil & Suncor & Total & $\begin{array}{l}\text { Trans } \\
\text { Canadá }\end{array}$ \\
\hline 1 & 1 & 1 & 1 & 1 & 1 & 1 & 1 & 1 \\
\hline 2 & 1 & 1 & 1 & 1 & 1 & 1 & 1 & 1 \\
\hline 3 & 1 & 1 & 1 & 1 & 1 & 1 & 1 & 1 \\
\hline 4 & 1 & 1 & 1 & 1 & 1 & 1 & 1 & 1 \\
\hline 5 & 1 & 0 & 0 & 0 & 0 & N/A & 0 & N/A \\
\hline 6 & 1 & 0 & 0 & 0 & 1 & 1 & 1 & 1 \\
\hline 7 & 1 & 1 & 1 & 1 & 1 & 1 & 1 & 1 \\
\hline 8 & 1 & 1 & 1 & 1 & 1 & 1 & 1 & 1 \\
\hline 9 & 1 & 0 & 0 & 1 & 1 & 1 & 1 & 1 \\
\hline 10 & 1 & 0 & 0 & 1 & 1 & 1 & 1 & 1 \\
\hline 11 & 1 & 1 & 1 & 1 & 1 & 1 & 1 & 1 \\
\hline 12 & 0 & 0 & 0 & 0 & 0 & 0 & 0 & 0 \\
\hline 13 & 1 & 1 & 1 & 1 & 1 & 1 & 1 & 1 \\
\hline 14 & N/A & N/A & N/A & N/A & N/A & N/A & N/A & N/A \\
\hline 15 & 0 & 0 & 0 & 0 & 0 & 0 & 0 & 0 \\
\hline 16 & 1 & 0 & 0 & 0 & 1 & 1 & 1 & 0 \\
\hline 17 & 1 & 0 & 0 & 0 & 0 & 0 & 0 & 0 \\
\hline 18 & $\mathrm{~N} / \mathrm{A}$ & $\mathrm{N} / \mathrm{A}$ & $\mathrm{N} / \mathrm{A}$ & $\mathrm{N} / \mathrm{A}$ & $\mathrm{N} / \mathrm{A}$ & $\mathrm{N} / \mathrm{A}$ & $\mathrm{N} / \mathrm{A}$ & $\mathrm{N} / \mathrm{A}$ \\
\hline 19 & 1 & 1 & 1 & 1 & 1 & 1 & 1 & 1 \\
\hline Total & 15 & 9 & 9 & 11 & 13 & 13 & 13 & 12 \\
\hline ID & $88 \%$ & $53 \%$ & $53 \%$ & $65 \%$ & $76 \%$ & $81 \%$ & $76 \%$ & $75 \%$ \\
\hline
\end{tabular}

Fonte: Elaboração Própria 
Apenas as empresas Eni e Exxon divulgaram os itens 12 - Resultado com investimentos avaliados pelo método de equivalência patrimonial e 15 - Valor do investimento em empresas contabilizado pelo método de equivalência patrimonial. Os itens relacionados ao Método de Equivalência Patrimonial (MEP) não são divulgados pelas outras empresas e isso está de acordo com o estudo de Nichols, Street e Cereola (2012) que identificaram decréscimo no nível de divulgação desses itens nas empresas da Europa relacionadas ao IFRS 8.

O item 16 - Total de adições a outros Ativos não Circulantes foi divulgado por sete das dezesseis empresas analisadas, sendo elas Eni, BP, Petrochina, Petrobras, Statoil, Suncor e Total. Já o item 17 - As bases de contabilização de transações intersegmentos foram divulgadas por nove empresas: BP, Chevron, CNOOC, Ecopetrol, Eni, Exxon, Imperial Oil, Petrobras e Petrochina.

O item 14 - Outro Itens Materiais de Resultado, usados pelo tomador de decisão e o item 18 - Existência de divergência na mensuração por segmento e societário não foram encontrados em nenhum dos relatórios analisados. Para evitar classificar erroneamente estes dois itens como não divulgados para todas as empresas, optou-se por tratá-los como Não Aplicáveis (N/A). Em relação ao item 14 pode ser que nenhuma empresa realmente tenha outros itens materiais usados para tomar decisões, porém há uma possibilidade de que as empresas não estejam divulgando estas informações por se tratar-se de informações estratégicas. Sobre o item 18, é mais aceitável a não divergência de mensuração por segmento e societário, pois isso pode gerar maiores custos às empresas.

No Quadro 5, são apresentadas a média do índice de divulgação das empresas da amostra, a média do índice de divulgação das grandes empresas, e as médias considerando os parâmetros de divulgação.

Quadro 5 - Médias do Índice de Divulgação para os anos de 2014 e 2015

\begin{tabular}{|cccc|}
\hline Empresas & Média ID & Parâmetro & Média ID \\
Amostra & $76 \%$ & Requisitos Mínimos & $88 \%$ \\
Grandes Empresas & $79 \%$ & Detalhamento & $69 \%$ \\
Demais Empresas & $74 \%$ & Mensuração & $56 \%$ \\
\hline
\end{tabular}

Fonte: Elaboração Própria

O índice médio de divulgação da amostra foi de 76\%, mostrando que, apesar da divulgação obrigatória, as normas ainda não são totalmente seguidas. As grandes empresas divulgaram em média $79 \%$ das informações por segmento, enquanto as demais possuíram nível médio de evidenciação de 74\%. Este resultado corrobora o estudo de Souza e Sarlo Neto (2014), que concluíram que quanto maior a empresa, maior o seu nível de divulgação, apesar de a diferença das grandes para as demais ser de apenas 5 pontos percentuais.

Quanto ao parâmetro, pode-se observar que os requisitos mínimos foram os que atingiram o maior nível de divulgação, com $88 \%$, enquanto o detalhamento apresentou $69 \%$ e a mensuração, o índice mais baixo, com $56 \%$. Esse baixo índice de divulgação corrobora o estudo de Weschenfelder e Mazzioni (2014), em que os índices de evidenciação são baixos, pois a definição dos parâmetros de como as informações são divulgadas é feita de maneira subjetiva.

O Quadro 6 apresenta o índice de divulgação por empresa, a quantidade de segmentos informados e se a divulgação é realizada por área de negócio ou por área geográfica.

Quadro 6: Índice de Divulgação, Quantidade e Tipo de Segmento dos anos 2014 e 2015

\begin{tabular}{|cccc|}
\hline Empresa & ID & $\begin{array}{c}\text { Quantidade } \\
\text { Segmento }\end{array}$ & Tipo de Segmento \\
Eni & $100,00 \%$ & 6 & Atividades \\
Exxon & $93,75 \%$ & 4 & Atividades \\
Petrochina & $88,24 \%$ & 5 & Atividades \\
BP & $82,35 \%$ & 3 & Geográfica \\
CNOOC & $82,35 \%$ & 3 & Atividades \\
Chevron & $81,25 \%$ & 3 & Atividades \\
Suncor & $81,25 \%$ & 3 & Atividades \\
Total & $76,47 \%$ & 6 & Geográfica \\
Statoil & $76,47 \%$ & 4 & Atividades \\
Imperial Oil & $75,00 \%$ & 3 & Atividades \\
TransCanada & $75,00 \%$ & 4 & Atividades \\
Petrobras & $70,59 \%$ & 5 & Atividades \\
Ecopetrol & $64,71 \%$ & 5 & Atividades \\
Sinopec & $64,71 \%$ & 5 & Atividades \\
Shell & $52,94 \%$ & 9 & Geográfica \\
Sasol & $52,94 \%$ & 5 & Atividades \\
\hline
\end{tabular}

Fonte: Elaboração Própria. 
É possível observar que o nível de evidenciação das empresas verticalmente integradas do ramo de petróleo e gás, no que diz respeito às informações por segmento, está acima de 50\%. Porém, esse índice não deve ser encarado como alto, pois como o foco do estudo é a divulgação obrigatória, todas as empresas deveriam apresentar índice de divulgação de 100\%.

Na sequência do maior para o menor, a Eni foi a única empresa que divulgou $100 \%$ dos itens obrigatórios. Em seguida vem a Exxon (93,75\%), a Petrochina (88,24\%), BP $(82,35 \%)$, CNOOC $(82,35 \%)$, a Chevron $(81,25 \%)$ e a Suncor $(81,25 \%)$ na faixa dos $80 \%$. Estas são as sete empresas com o maior índice de divulgação. No final da lista, com os menores índices, aparecem a Ecopetrol e a Sinopec, ambas com 64,71\%, e depois a Shell e Sasol com 52,94\%, ou seja, com divulgação de um pouco mais da metade exigida pelas normas.

O entendimento sobre a apuração de índices de divulgação abaixo de $100 \%$ passa por dois aspectos principais. Primeiro, conforme Healy e Palepu (2001), que a regulação, ao estabelecer quesitos obrigatórios a serem seguidos pelas empresas, tende a reduzir a lacuna informacional entre as pessoas com e sem informação por meio da criação de requerimentos de disclosure, o que levaria ao entendimento de que os índices de divulgação deveriam atingir os mais altos patamares, senão os $100 \%$. No entanto, sob um segundo aspecto, é sabido que os gestores possuem incentivos próprios, diversos dos proprietários e demais usuários das informações, e que os levam às escolhas contábeis sobre o que divulgar e como divulgar, mesmo em um ambiente regulado (DYE, 1986).

Foi feito o levantamento da quantidade de segmentos divulgados para verificar, qualitativamente, possíveis associações com o índice de evidenciação. O Quadro 6 evidencia certa dispersão da quantidade de segmentos ao comparar com o ID. Verifica-se que a Shell, apesar de ser a empresa que apresenta a maior quantidade de segmentos (nove), foi a que registrou menor índice de divulgação. Por outro lado, entre as empresas com maiores IDs, a Eni possui seis segmentos, enquanto a Exxon e Petrochina dispõem de quatro e cinco segmentos, respectivamente.

Outra análise realizada foi verificar se a empresa divulga por área de negócio ou por área geográfica. Foi identificado que das dezesseis companhias analisadas apenas três divulgam por área geográfica (BP, Shell e Total) e a maioria, por área de negócio. Esse resultado também está de acordo com o estudo de Nichols, Street e Cereola (2012), o qual identifica que a maioria das empresas europeias divulga por segmento de negócio em vez de região geográfica, e não fazem a reconciliação das informações por segmento com as demonstrações consolidadas conforme exigido pelo IFRS 8.

\section{CONCLUSÃO}

A presente pesquisa teve como objetivo verificar o nível de divulgação das empresas de óleo e gás, verticalmente integradas, em relação às normas contábeis de informações por segmento (SFAS 131 e IFRS 8).

Os resultados mostraram que, apesar da obrigatoriedade e da forte recomendação por parte dos órgãos normativos, apenas uma, das dezesseis empresas analisadas, apresentou índice de divulgação de $100 \%$. A média geral foi de $76 \%$, evidenciando que as empresas não estão aderentes aos requerimentos das normas.

Algumas empresas apresentaram baixo índice de divulgação, como a Sasol e Shell. Não é possível inferir sobre os incentivos existentes para esse baixo nível de divulgação ou se existe falta de interesse dessas empresas em repassar a informação de forma mais consistente, ficando como sugestão de estudos futuros essa vertente de pesquisa.

Qualitativamente, parece que os índices de divulgação não são influenciados pelas quantidades e tipos de segmentos, ou seja, existem indícios de que, independentemente de a empresa divulgar muitos ou poucos segmentos, não há relação com o seu nível de evidenciação, assim como por atividade ou área geográfica. A comprovação, contudo, só poderia vir mediante testes estatísticos robustos, o que não foi realizado neste trabalho em função da reduzida amostra para esse tipo de teste.

Ao analisar o nível de divulgação das empresas de petróleo e gás listadas na NYSE, verticalmente integradas, quanto às normas IFRS 8 e SFAS 131 de informações por segmento, pôde-se inferir que ainda são necessários estudos para suportar o entendimento do processo da regulação contábil frente àquilo que as empresas vêm divulgado. Estudos sobre índice de divulgação das empresas são pertinentes não só para verificar se estão divulgando ou não as informações requeridas, mas também para chamar a atenção sobre como os processos atuais estão acontecendo. Nesse particular, estudos anteriores mostraram, como se vê no presente trabalho, que o atendimento aos requerimentos normativos é baixo, não atingindo os $100 \%$ esperados. Esses achados podem indicar que, na prática, o que os órgãos reguladores como FASB e IASB idealizaram como informações requeridas pelos usuários não é exatamente o almejado, uma vez que não são claras as demandas pelas informações, nesse particular, as informações por segmento, por parte dos usuários. Pelo contrário, há indícios de excesso de informação divulgada, como aponta Cazzari (2013).

Este estudo entra em discordância com o de Fernandes (2009), que demonstrou que os itens divulgados pelas empresas petrolíferas verticalmente integradas estavam aderentes às normas, e que $90 \%$ deles alcançaram a melhor classificação na escala de atendimento proposta. Uma possível explicação reside no fato do período escolhido. Diferentemente do período coberto por Fernandes (2009), os anos de 2014 e 2015 foram difíceis para as empresas petrolíferas dada a queda nas cotações dos preços do petróleo e derivados. Em cenário de baixa rentabilidade, os gestores podem escolher divulgar menos informações para encobrir as razões dos prejuízos ou quedas dos lucros (SINGHVI; DESAI, 1971; LANG; LUNDHOLM, 1993).

As principais limitações deste estudo foram a coleta de dados e a metodologia análise de conteúdo, dada a subjetividade dos pesquisadores no momento da apuração. Como sugestões de pesquisas futuras, além da citada, propõe-se 
verificar os fatores que podem influenciar no índice de divulgação e promover a comparação dos índices de divulgação de empresas de mercados diferentes.

\section{REFERÊNCIAS}

AILLÓN, H. S.; SILVA, J. O.; PINZAN, A. F.; WUERGES, A. F. E. Análise das informações por segmento: divulgação de informações gerenciais pelas empresas brasileiras. Revista Contemporânea em Contabilidade - UFSC. Florianópolis, v. 10, n. 19, p. 33-48, jan./abr. 2013.

ALMEIDA, J. E. F. Qualidade da informação contábil em ambientes competitivos. 2010. Tese (Doutorado em Controladoria e Contabilidade) - Programa de Pós-Graduação em Ciências Contábeis, Faculdade de Administração, Economia e Contabilidade da Universidade de São Paulo. São Paulo, 2010.

ALMEIDA, E. L. F; OLIVEIRA, P. V.; LOSEKANN, L. Impactos da contenção dos preços de combustíveis no Brasil e opção de mecanismos de precificação. Revista de Economia Politica v. 10, n. 3, p. 531-556, jul./set. 2015.

BALL, R.; KOTHARI, S. P.; ROBIN, A. The effect of international institutional factors on properties of accounting earnings. Journal of Accounting and Economics. v. 29, p. 1-51, fev. 2000.

BARTH, M. E.; LANDSMAN, W. R.; LANG, M. H. International accounting standards and accounting quality. Journal of Accounting Research v. 46, n. 3, p. 467-498, jun. 2008.

BEAVER, W. H. Financial reporting: an accounting revolution. New Jersey: Prentice-Hall, 1998.

BOSCOV, C. P. O enfoque gerencial na divulgação de informações por segmento. 2009. Dissertação (Mestrado em Controladoria e Contabilidade) - Faculdade de Economia, Administração e Contabilidade da Universidade de São Paulo. São Paulo, 2009.

BROWEN, R. M.; DUCHARME, L.; SHORES, D. Economic and industry determinants of accounting method choice. (Working Paper). University of Washington Business School, 1999.

CAZZARI, R. B. A compreensibilidade das informações contábeis e sua relação com os custos de transação sob a óptica dos profissionais de investimento. 2013. Dissertação (Mestrado em Controladoria e Contabilidade) - Programa de Pós-Graduação em Ciências Contábeis, Faculdade de Administração, Economia e Contabilidade da Universidade de São Paulo. São Paulo, 2013.

CHUNG, D. Y. The informational effect of corporate lobbying against proposed accounting standards. Review of Quantitative Finance and Accounting. v. 12, n. 3, p. 243-269, maio 1999.

COLLIS, J.; HUSSEY, R. Pesquisa em administração: um guia prático para alunos de graduação e pós-graduação. 2. ed. Porto Alegre: Bookman, 2005.

COMITÊ DE PRONUNCIAMENTOS CONTÁBEIS (CPC). Pronunciamento técnico CPC 22 - Informações por segmento. Brasília, 2009.

CHRISTIE, A. A.; ZIMMERMAN, J. L. Efficient and opportunistic choices of accounting procedures: corporate controls contests. The Accounting Review v. 69, n. 4, p. 539-566, out. 1994.

DYE, R. A. Proprietary and nonproprietary disclosure - part 1. The Journal of Business. v. 59, n. 2, p. 331-336, abr. 1986.

EMMANUEL, C. R.; GARROD, N. On the relevance and comparability of segmental data. Abacus, v. 38, n. 2, p. 215-234, jun. 2002.

FERNANDES, L. J. D. Segmentação de negócios: fonte de informação para os usuários das demonstrações contábeis de empresas petrolíferas. 2009. Dissertação (Mestrado em Ciências Contábeis) - Centro de Ciências Jurídicas e Econômicas, Faculdade de Administração e Ciências Contábeis, Universidade Federal do Rio de Janeiro, Rio de Janeiro, 2009.

FIELDS, T. D.; LYS, T. Z.; VICENT, L. Empirical research on accounting choice. Journal of Accounting and Economics. v. 31, p. 255-307, jan. 2001.

FINANCIAL ACCOUNTING STANDARDS BOARD. Statement of financial accounting standards 14: Financial reporting for segments of a business enterprise. dez. 1976.

Statement of financial accounting standards 131: disclosures about segments of an enterprise and related information. jun.1997.

GIL, A. C. Como elaborar projetos de pesquisa. 3. ed. São Paulo: Atlas, 1991.

HEALY, P. M.; PALEPU, K. G. Information asymmetry, corporate disclosure, and the capital markets: A review of the empirical disclosure literature. Journal of Accounting and Economics, v. 31, n. 4, p. 405-440, 2001.

INFORMATION HANDLING SERVICES. Energy 50: The definitive annual ranking of the world's largest listed energy firms. Jan. 2014. Disponível em: <https://cdn.ihs.com/www/energy50/IHS-Energy-50-Final-2014.pdf>.

INTERNATIONAL ACCOUNTING STANDARDS BOARD. International Financial Reporting Standards 8: operational segments. nov. 2006. International Accounting Standard 14: segment reporting. ago. 1997.

KING, T. A. More than a numbers game: a brief history of accounting. New Jersey: Wiley, 2006.

KOTHARI, S. P.; RAMANNA, K.; SKINNER, J. S. Implications for GAAP from an analysis of positive research in accounting. Journal of Accounting and Economics. v. 50, n. 2-3, p. 246-286 dez. 2010.

KOU, W.; HUSSAIN, S. Predictive gains to segmental disclosure matrices, geographic information and industry sector comparability. The British Accounting Review, v. 39, n. 3, p. 183-195, set. 2007.

LANG, M.; LUNDHOLM, R. Cross-sectional determinants of analyst rating of corporate disclosure. Journal of Accounting Research. v. 31, n. 2, p. 246-271, 1993. 
LEV, B. Toward a theory of equitable and efficient accounting policy. The Accounting Review. v. 63, n. 1, p. 1-22. 1988.

LEVITT, A. The importance of high quality accounting standards. Accounting Horizons. v. 12, n. 1, p. 79-82, mar. 1998.

MALONE, D.; FRIES, C.; JONES, T. An empirical investigation of the extent of corporate financial disclosure in the oil and gas industry. Journal of Accounting, Auditing \& Finance. v. 8, n. 3, p. 249-273, jul. 1993.

MOURAD, N. A. IFRS 8: segmentos operacionais: contabilidade internacional: International Financial Reporting Standards - IFRS. São Paulo: Atlas, 2009. (Série academia-empresa; 7).

MURCIA, F. D.; SANTOS, A. Fatores determinantes do nível de disclosure voluntário de companhias abertas no Brasil. Revista de Educação e Pesquisa em Contabilidade, v. 3, p. 72-95, 2009a.

MURCIA, F. D.; SANTOS, A. Regulação contábil e a divulgação de informações de operações com instrumentos financeiros derivativos: análise do impacto da CVM n ${ }^{\circ}$. 566/08 e da CVM n ${ }^{\circ}$ 475/08 no disclosure das companhias abertas no Brasil. Revista de Contabilidade e Organizações, v. 3, n. 6, p. 3-21, maio/ago 2009b.

NEW YORK STOCK EXCHANGE. Current List of All Non-U.S. Issuers. 2017. Disponível em: <https://www.nyse.com/publicdocs/ nyse/data/CurListofallStocks.pdf>. Acesso em: 15 abr. 2017.

NICHOLS, N. B.; STREET, D. L.; CEREOLA, S. J. An analysis of the impact of adopting IFRS 8 on the segment disclosures of European blue chip companies. Journal of International Accounting, Auditing and Taxation, v. 21, n. 2, p. 67-90, 2012.

PERLINGEIRO, B. C. L. Teoria das escolhas contábeis: fair value de derivativos em bancos no Brasil. 2009. Dissertação (Mestrado em Controladoria e Contabilidade) - Programa de Pós-Graduação em Ciências Contábeis, Faculdade de Administração, Economia e Contabilidade da Universidade de São Paulo. São Paulo, 2009.

POHLMANN, M. C.; ALVES, F. J. S. Regulamentação. In: IUDÍCIBUS, S.; LOPES, A. B. (Orgs.). Teoria avançada da contabilidade. São Paulo: Atlas, 2004. p. 233- 273.

ROSS, M. L. A maldição do petróleo. 1. ed. Porto Alegre: CDG, 2015

SCHVIRCK, E. Relatórios por segmento publicados pelas companhias de capital aberto no Brasil: os efeitos da divulgação no desempenho das empresas. 2014. Tese (Doutorado em Administração) - Centro Socioeconômico, Universidade Federal de Santa Catarina, Florianópolis, 2014

SCHVIRCK, E.; LUNKES, R. J.; GASPARETTO, V. Divulgação de Informações por segmento: panorama da aplicação do CPC 22. Revista de Educação e Pesquisa em Contabilidade, Brasília, v.7, n.2, p. 131-146, abr./jun. 2013.

SECURITIES AND EXCHANGE COMMISION. Washington, 2017. Disponível em: <http://www.sec.gov/edgar>. Acesso em 15 abr. 2017.

SENA, J. P. S. O impacto do petróleo na dinâmica socioeconômica mundial. 2016. Monografia (Graduação em Engenharia de Petróleo). Universidade Federal do Rio Grande do Norte. Natal, 2016.

SILVA, P. D. A.; MARQUES, J. A. V. C; SANTOS, O. M. Análise da evidenciação das informações sobre o impairment dos ativos de longa duração de empresas petrolíferas. Revista BASE, v. 6, p. 258-274, 2009.

SINGHVI, S. S.; DESAI, H. B. An empirical analysis of the quality of corporate financial disclosure. The Accounting Review v. 46, n. 1 , p. $129-138$, jan.1971.

SOUZA, J. A.; SARLO NETO, A. Práticas de Divulgação de informações sobre segmentos operacionais no Brasil. Sociedade, Contabilidade e Gestão, Rio de Janeiro, v. 9, n. 2, p. 40-57, maio/ago. 2014.

STIGLER, G. J. The theory of economic regulation. The Bell Journal of Economics and Management Science, v. 2, n. 1, p. 3-21. 1971.

TALHA, M.; SALIM, A. S. A. What prompts firms to choose between business and geographic segments as a primary segment? Managerial Auditing Journal, v. 25, n. 1, p. 17-31, 2010.

VASCONSELOS, M. G.; SZUSTER, N. Informações Contábeis por Segmento de Negócios. Revista de Contabilidade do Mestrado em Ciências Contábeis da UERJ, Rio de Janeiro, v.8, n. 2, p. 71-88, 2003.

VIEIRA, R. T; BORBA, J. A. Cartas de comentários das empresas enviadas ao IASB: uma análise da revisão pós-implementação do IFRS 8 - operating segment. Revista Contabilidade e Controladoria, Curitiba, v. 7, n. 1, jan./abr. 2015.

WATTS, R. L. Accounting choice theory and market-based research in accounting. The British Accounting Review, v. 24, n. 3, p. 235-267, set.1992.

WESCHENFELDER, C.; MAZZIONI, S. Informações por Segmento: análise do nível de evidenciação das companhias listadas no novo mercado. Revista Catarinense da Ciência Contábil, Florianópolis, v.13, n.39, p. 21-33, maio/ago. 2014. 